\title{
Redox evolution of Fe and biomineralization of secondary Fe minerals in lake sediments
}

\author{
Huan LiU Xiancai Lu XiangJie Cui ${ }^{1}$ \\ ${ }^{1}$ School of Earth Sciences and Engineering, Nanjing \\ University, Nanjing, Jiangsu 210023, China \\ (huanliu_earth@hotmail.com,xcljun@nju.edu.cn, \\ MG1829069@smail.nju.edu.cn)
}

Iron $(\mathrm{Fe})$ minerals are ubiquitously occur in lake sediments and the biogeochemical cycling of $\mathrm{Fe}$ play important roles in supergene environment, controlling the geochemical behavior of $\mathrm{C}, \mathrm{N}, \mathrm{S}$ and other trace elements. The evolution and transformation of Fe minerals with depth could act as the key indication to reveal the redox conditions of sediments.

In this study, secondary Fe minerals in Lake Tai (Eastern China) sediments were characterized using high-resolution microscopy. Goethite and greenrust were investigated as the main $\mathrm{Fe}(\mathrm{III})$-bearing oxides in the surfical sediment in $0-1 \mathrm{~cm}$. Pyrite particles were observed with random morphologies in 3-4 cm and ultimately grew as the cubic and octahedral pyrite crystals and pyrite framboids in deeper sediments, indicating the microbial reduction of sulfur occurred in shallow sediments. Siderite, resulted from the microbial degradation of organic carbon and the diagenesis of inorganic carbon, was found to appear in deeper sidement at $85 \mathrm{~cm}$. The siderite particles contain high contents of $\mathrm{Mn}$ and aggregated with clays and calcium carbonate to reach $1-2 \mu \mathrm{m}$ and grew to larger aggregates in deeper. The oxidation state of Fe and $\mathrm{Mn}$ was characterized using the X-ray absorption spectroscopy (XAS) that the ratio of $\mathrm{Fe}(\mathrm{II}) / \mathrm{Fe}(\mathrm{III})$ increased with the depth and showed the spectral feature of pyrite, indicating the microbial reduction of $\mathrm{Fe}$ in deep sediments. Mn was found to be the mixture of $\mathrm{Mn}$ (II) and $\mathrm{Mn}$ (III/IV) in surfical sediment and only in $\mathrm{Mn}(\mathrm{II})$ with the increase of depth. The oxidation state of $\mathrm{Fe}$ in microscale was also investigated using scanning transmission X-ray microscopy (STXM) that the $\mathrm{Fe}$ in clay minerals were mainly $\mathrm{Fe}(\mathrm{III})$ in the sediment profiles. A geochemical model of transformation pathways of Fe minerals and the change of redox conditions of lake sediments were propsed that the microbial reduction of $\mathrm{Fe}$ and $\mathrm{S}$ led to pyrite in shallow sediments while siderite became the dominate $\mathrm{Fe}$ phase with the increase of dpeth, consistent well the geochemical behavior of S and C.

Acknowledgements: This work is financial supproted by the National Science Foundation of China (Grant No. 41730316). 